\title{
85601 - PERFIL DOS PACIENTES IDOSOS AVALIADOS PARA DISFAGIA OROFARÍNGEA
}

\author{
Apresentação Oral - Gerontologia
}

\author{
Guilherme Briczinski de Souza / Souza, GB / UFCSPA; \\ Anna Carolina Angelos Cardoso / Cardoso, ACA / UFCSPA; \\ Sheila Tamanini de Almeida / Almeida, ST / UFCSPA
}

Introdução: O processo de envelhecimento envolve um conjunto de modificações fisiológicas que favorecem o surgimento de multimorbidades. Dentre elas, pode-se encontrar a disfagia orofaríngea que pode estar associada à desnutrição, desidratação e aos riscos de broncoaspirações, prejudicando na qualidade de vida do idoso e no tempo de internação, quando já hospitalizados. Dessa forma a utilização de protocolos de investigação de disfagia orofaríngea permite que sejam identificados sinais e sintomas associados a este distúrbio de deglutição, permitindo otimizar a internação hospitalar e favorecer a alta melhorada. Objetivo: Caracterizar o perfil dos pacientes idosos avaliados por um protocolo de investigação de disfagia orofaríngea em um hospital na cidade de Porto Alegre, nos anos de 2017 e 2018. Metodologia: Estudo do tipo transversal e retrospectivo, realizado por meio da análise dos protocolos de avaliação de disfagia orofaríngea. Investigação aprovada pelo comitê de ética da UFCSPA sob no 3125527. As variáveis analisadas foram: sexo, idade, diagnostico medico, motivo e resultados da avaliação. Resultados: A amostra foi composta por 61 prontuários. Destes, 50,8\% eram do sexo masculino. Observou-se que a média de idade foi de 71,3 anos. Em 19,6\%, o acidente vascular cerebral isquêmico foi o diagnóstico médico mais frequente. A reintrodução de alimento por via oral foi o motivo de avaliação mais prevalente em $32,6 \%$ dos casos, seguido pela progressão da dieta em 23,9\% da amostra. Na variável dificuldade em se alimentar, houve dificuldade na consistência sólida em $23,07 \%$ e também na consistência liquida em 23,07\%. Quanto a presença de tosse, engasgo e/ou sufocamento, ela foi identificada em 45,9\% dos idosos avaliados. A conclusão fonoaudiológica mais prevalente foi a de disfagia leve com baixo risco de aspiração e de disfagia moderada com risco de aspiração, ambas com 29,4\% da amostra. Conclusão: Foi evidenciada alta frequência de tosse, engasgo e/ou sufocamento, o que corrobora com as mudanças morfofisiológicas do envelhecimento, que podem levar a uma deglutição alterada. Observamos um alto índice de diagnóstico de disfagia orofaríngea, assim, torna-se muito importante a realização da avaliação da deglutição neste público, para que essas dificuldades e alterações, quando encontradas, sejam tratadas precocemente. 